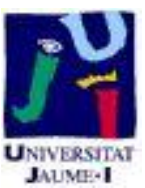

Título artículo / Títol article: Re-framing the subject(s) of gender violence

Autores / Autors

Gámez Fuentes, María José

Revista:

Peace Review: A Journal of Social Justice, 2013, Volume 25, Issue 3

Versión / Versió:

Post-print del autor

Cita bibliográfica / Cita

GÁMEZ FUENTES, María José. Re-Framing the bibliogràfica (ISO 690): Subject (s) of Gender Violence. Peace Review, 2013, vol. 25, no 3, p. 398-405.

url Repositori UJI:

http://hdl.handle.net/10234/94280 


\title{
Re-framing the subject(s) of gender violence
}

\author{
María José Gámez Fuentes
}

The concern to eradicate violence against women is not new in the global agenda. In the search and struggle for a more equitable and peaceful world, the feminist movement has undoubtedly been the main driving force behind the changes produced. From diverse grassroots women's movements against any kind of violence towards women (rape, battering, war or poverty, among others) to institutionalized feminist policies and NGOs working to combat gender-based violence, women's organizations and initiatives have been able to raise awareness and articulate a demand to place gender-based violence at the core of political agendas. By having placed the collective and collective organization at the heart of the debate, women's movements have sought not only to address direct violence, but also to transform the very frames sustaining its intelligibility.

Since 1975, the United Nations Commission on the Status of Women has been responsible for the different conferences on women, taking place in Mexico (1975), Copenhagen (1980), Nairobi (1985) and Beijing (1995). In 1979, the United Nations General Assembly approved the Convention on the Elimination of all Forms of Discrimination against Women (CEDAW). In 1993, the Declaration on the Elimination of Violence against Women underwent the same process. Furthermore, in the 1995 Beijing Conference, the 189 participating states signed the Declaration and Platform for Action so that governments would redress women's unequal position in several critical areas. Violence and human rights were prominent target areas included in this agenda. Under this Declaration, the neglect of women's rights was designated as a human rights violation. The declaration promoted gender mainstreaming policies and actions in order to achieve equality and eradicate gender-based violence.

According to the United Nations, and despite all of these efforts, violence against women and girls is one of the most widespread violations of human rights. In some countries, seven out of ten women will suffer some form of gender-based violence during their lifetime. Along this vein, Amnesty International highlights that "despite the obligation of the states to act with due diligence to prevent violence against women, violence against women and girls in many societies is met with governmental silence or apathy or lack of interest." However, it is important to mention that even the states that adopt legislation to prevent and sanction violence against women fail to face the issues adequately and effectively. With regards to policy developments on violence against women, the 2011 European Women's Lobby's Barometer emphasizes "the persistent lack of political will to end violence against women in Europe [and] highlights the European tolerance for violence against women." Let us take the case study of Spain as an example. Spain was one of the seventeen participating states in the expert group meeting on good practices in legislation to address violence against women, the results of which were published by the UN in the Handbook for Legislation on Violence against Women in 2010. Moreover, in this document, it is one of the countries mentioned as an example for its advanced legislation in gender violence. Indeed, in conjunction with the Organic Act on Integrated Protection Measures against Gender Violence (2004), a number of other laws have been amended in order to ensure consistency in Spain, such as the Worker's Statute, Social Offences and Sanctions Act and Criminal Code. Since then, the Organic Law for Gender Equality was also approved 
in 2007 to strengthen the project for eradicating discrimination and violence against women. Related mostly to domestic violence, the Spanish media has incorporated gender violence issues into its agenda. News reports, talk shows, magazines and documentaries, for example, tackle these issues and expose them to the general audience.

Despite this array of legal measures, advertising campaigns, media reports and programs, they have not had the desired impact on Spanish public awareness, as demonstrated by the Sociological Research Centre Barometer (Barómetro del Centro de Investigaciones Sociológicas). This is disheartening. It has gradually decreased since 2004, the year when the Organic Act against Gender Violence was approved. These results are clearly demonstrating that something is going wrong, particularly since the increase in the political and communicative efforts does not match the awareness raised. One could argue that Spanish law does not seem to have had an impact on the transformation of the everyday lives of people.

This conclusion, however, cannot be inferred only from this particular Spanish context, but rather it is symptomatic of the present state of affairs. The main theme of the $57^{\text {th }}$ Session of the United Nations Commission on the Status of Women (4-15 March 2013, New York) is ending violence against women. In preparation for this, an online discussion on transforming social norms to prevent violence against women and girls was set up through a wikigender site. According to the background information provided by this site, there has been considerable progress in many areas and countries. However, the Organisation for Economic Co-operation and Development (OCDE) Centre's 2012 Social Institutions and Gender Index (SIGI) also observes that discriminatory social norms and practices undermining gender equality remain persistent and contribute to violence against women. In this context, it is even more surprising to find that violence against women is not included among the UN Millennium Development Goals, although complementary efforts have been taken in order to make explicit the commitment of the MDG with this cause.

In this regard, a contradiction seems to exist between the progress achieved in legal terms to sanction violence and the underlining cultural violence that permeates everyday life. If the pervasiveness of violence is such in spite of legal frameworks aimed at its eradication, the issue then arises as to whether the way violence against women has been tackled has really changed the cultural imaginary that sustains it.

On the one hand, and following Judith Butler's standpoint, it is necessary to ask ourselves whether full responsibility has been apportioned once legal responsibility has been assumed. Undoubtedly, we need to implement a jurisdiction to deal with aggressors and social and health policies to support women survivors. However, thus far, the way gender violence has been made visible and dealt with has not modified the sexist fabric of culture that enables it and the endless number of murders and abuses.

On the other hand, in spite of the work of women's organizations to combat violence against women and international efforts to empower women as agents in the construction of peace and the transformation of conflicts, when it comes to the portrayal of gender violence and its victims, the representation of women in institutional campaigns and mainstream culture reproduces a frame of recognition that duplicates symbolically the victimization originally suffered. For women not only appear as victims, which they are, but also as devoid of agency, a direct result of the ways in which their appearances and testimonies are framed in these cultural contexts.

Specialized literature on this matter observes that the mise en scene constructed by news, campaigns, reports and mainstream audiovisual culture in general share 
similarities that configure a disempowering scenario. In media reports, abuse, mostly domestic and almost exclusively heterosexual and physical (resulting or not in death), is the main focus of the stories. Female subjectivity and the female body are represented in association to being wounded or killed, even in institutional campaigns against violence. These narratives fail to challenge the hegemonic matrix that links female subjectivity to subjugation before violence. Even when female agency is represented, it is mainly articulated through reporting or through women allowing themselves to be helped, but only when previously having reported the abuse. In cases of domestic violence, physical abuse is never contextualized within the more general framework of human rights violation, discrimination, structural and cultural violence against women or other cases of abuse (rape, women as weapons of war, human trafficking). Instead, family members, neighbors, passer-byes or friends of the victimizer are questioned about his individual circumstances (drugs, jealousy, illness) for committing the abuse or crime. This, in turn, supports the reasoning that aggression is dependant upon a very particular set of individual characteristics. Finally, emphasis is placed on the violent and tragic aspects of the aggression (bruises, weapons used and wounds) and the victim's acts or omissions, which may have contributed to the violence. Even in the last UN Campaign UNiTE to End Violence Against Women, a survivor's video can be found on its web page (http://www.un.org/en/women/endviolence) in which women provide testimony to the brutalities they have suffered.

Moreover, according to the last and largest global study on violence against women published by the American Political Science Review in 2012, it is internationally agreed that gender violence affects women of any demographic origin. Nevertheless, when we visit the web page of the UN Trust Fund to End Violence Against Women, we find that under the section News and Stories, 19 out of 23 reports are dedicated to women from or impoverished countries in Africa (South Africa, Liberia, Ethiopia), Latin America (Peru and Guatemala), Asia (India, Nepal, Cambodia) and the Roma people in Eastern Europe.

At this point, I firmly believe that the time has come to revise the institutional and cultural framework that emanates from the narratives on gender violence. It is important to raise awareness about the damage that may be inscribed in and can be inflicted by the very ways in which gender violence has been institutionally approached and culturally framed. Thus, a revision is needed in order to resituate the debate with respect to the modes of subjectification enabled by political and media approaches.

As Adelman observes, "the globalization of domestic violence and the resultant association and identification of women with victimization may delimit the agency of women [...] and/or may funnel funds toward anti-violence initiatives without providing support for eradicating the conditions that make women vulnerable to violence and men entitled to maintain authority through violence in the first place." The same could be said of the globalization of gender-based violence. Further studies sustain that the criminalization and medicalization of gender violence have contributed to its neutralization. The typification of violence and its resolution by juridical means avoids holding the social structure responsible for the inequalities that lead to violence. As gender violence is indeed a human rights violation, legal and social measures to address the matter should be implemented. However, in order to transform the agency of the victim implicated in the matter, states, organizations and the community should be interpellated in order to confront the double victimization of women.

In this context, we would like to recuperate Catia Confortini's contribution on the need to incorporate Feminist Studies into Peace Studies, with particular regard to further developing and enhancing theories on violence from a gender perspective. Let us 
remember that, according to Galtung, violence is manifested in direct, structural and cultural modes. Gender is but one variable in the analysis of violence. However, as Confortini argues, violence needs to be seen as a process of social practices embedded in language and social institutions and constructed in power relations that are themselves gendered. Therefore, debates on the construction of peace cultures cannot be undertaken regardless of the violence of gender. Violence is constituted by and constitutive of gender relations of power, independently of these taking place in domestic, international or military contexts.

In this analytical framework, the violence of gender is assumed as constitutive of the fabric of politics and culture and thus has important implications for Peace Studies. First and foremost, jurisdiction, social services and health policies to combat violence against women, although needed, are insufficient. In order to transform gender-based conflicts and violence, a systemic process involving significant changes in societies and societal institutions needs to be addressed. Such changes cannot be pursued without recurring to alternative modes of intervention. In this respect, patronizing narratives that render women unable to attain a subject position (unless they are being protected and safeguarded by the system) need to be substituted by the recognition of the capacity of women as agents of their own survival and change. Patronizing narratives not only configure gender violence upon individual and testimonial cases, but also conceal the driving force of the collective commitment and struggle of women's movements to intervene in the transformation of the lives of women in the face of the violence of hetero-normativizised societies.

Despite hegemonic configurations and matrixes of recognition, violence is not something that occurs to particular women in specific circumstances. Tragedy is not the only outcome of women who try to break the silence. Protecting women and sanctioning victimizers cannot be the only options available for transforming the problem. Violence against women (symbolic, cultural, economical or physical, among other types) results from holding unequal and gendered power positions, which are supported and reproduced by society. Therefore, intensive efforts on prevention and capacity building should be pursued. We need a conflation of political and interpersonal initiatives. How can a gender and peace studies approach contribute to it? So far, we seem trapped in the same juncture that Teresa De Lauretis denounced in the eighties: the way gender violence has been made visible has failed "to analyze the terms of its own enquiry, especially terms such as family, power and gender." There is no doubt that states (although unevenly) have responded to the call of feminist movements by including in their political agenda the prosecution of aggressors and the establishment of social policies to help women. However, a real transformation of the gender conflict that sustains it cannot be pursued without confronting the unequal power structures that conform life at its basis.

At this juncture, Judith Butler's reflection on the concept of accountability may lead us to act upon innovative lines of theoretical, political and cultural intervention. The hegemonic matrix of gender violence places woman as a victim that is interpellated to give account of her ordeal before the law (through the denouncement) or her culture (through mediatized testimonies). In this respect, gender violence is configured through the recourse to the individuality of the female subject who is asked to give her personal account of the aggression. Aggression is linked to a personal testimony and thus, disconnected from structural and cultural violence. Moving from this 'gender violencesingular victim-personal accountability' configuration and putting it into debate with the 'social injustice-anonymous indignant-collective accountability' (in the context of the 
topic that centers the discussion of this volume), it is my contention that the imaginary elaborated around the figure of the 'indignant' can give us clues to construct new political, interpersonal/collective and cultural strategies. Whereas the imaginary around the figure of the indignant thematizes relationality, the figure of the victim is constructed upon the fallacy of the sovereign subject. Indeed, our knowledge on gender violence has been compromised by approaches privileging the modern idea of the free, autonomous, rational and sovereign subject. From this perspective, women impacted by violence are considered to be subjects who possess the ability and right to freely denounce and fight their situation. This configuration remains oblivious of the complex relations of heteropatriarchal dependency that sustain our everyday lives. Women are interpellated to give account of a violence that is beyond their comprehension, since the conditions that sustain the violence exceed a purely personal or idiosyncratic meaning. The issue does not amount to whether or not women are aware of the violence inflicted upon them. Indeed, women are perfectly knowledgeable about the violence they have suffered. The problem lies in the fact that we are not given the tools to understand the gender trouble (in Butler's words) that sustains it or to find non-unidirectional ways to transform the conflict in a nonviolent manner.

In this context, I consider a third element, apart from the victim and the aggressor, which comes into play in the construction of violence and needs to be researched further: the witness (understood as either the community or the media). By introducing this third subjectivity, we can explore innovative ways to implicate, on the one hand, the community in preventing violence and restoring justice and, on the other, the media in bearing witness to the subjects it represents so it does not disempower them through victimization and instead activates ethical responses from its spectators.

\begin{abstract}
Along these lines, I suggest bringing capacity building and a collective commitment for justice to the forefront of this debate. Since these have been the cornerstones of the work from diverse movements of international women's rights, it seems paradoxical that, when policies have been implemented, the representation of women has been diminished in favor of the state and its patronizing narratives. Thus, this more nuanced and multi-dimensional conceptualization does not merely focus on legal, medical or social services informed approaches, which configure women as recipients (not agents) of state intervention and feed the disempowering and victimizing perspectives adopted by everyday images. Instead, we need to question the hegemonic patterns of visibility and invisibility that have been articulated in processes of gender violence with respect to the possibilities for accountability, empowerment, competency building and restoration of justice jeopardized by unequal gendered relations.

In the realm of representation, we advocate for what Kelly Oliver terms "ethical witnessing dynamics." It consists of bearing witness to the other's testimony beyond recognition, that is, by resisting the act of subsuming it within a recognizing matrix. Ethical witnessing implies adding political value to the act of spectatorship and holding the witness responsible towards the other. This means we need to construct narrative fractures by refusing both to ask the survivor for the reasons of putting up with the aggression (since women's actions are not the enigma to be disclosed by an inquisitive agent/actor) and to frame the aggressor as a monster or transgressor of the social law (since the social law foments sexism and all kinds of gender-based violence). On the other hand, satisfactory narrative closures (=answer) to the problem, through the recourse to penal, medical or social services outcomes, should be avoided. Otherwise it will not be possible to break away from a moral enquiry delineated by the conditions that generate it.
\end{abstract}


Within this proposal, narratives should also assume the impossibility of the "self" to narrate itself fully. As Butler says in Giving account of oneself: "[...] there is no ' $\mathrm{I}$ ' that can fully stand apart from the social conditions of its emergence, no ' $\mathrm{I}$ ' that is not implicated in a set of conditioning moral norms." Hence, by thematizing and prioritizing the relations of dependency and control that condition our most private and quotidian relations (and which have been made opaque under everyday culture formations), we highlight our fundamental need to address the other and be addressed by the other. It is from this perspective that the connections between women's movements against violence and everyday cases should be displayed.

In sum, the key for discussing how to radically transform gender violence by peaceful means lies in addressing the competencies that survivors along with the local and global community need to build in order to de-activate the sovereignty of self and violence. Thus, we activate, instead, a collective responsibility for transforming the structural gender issue so that conflict can be "occupied" in a different way. In this manner, we are able to activate in the citizenry and the media, as witness, the need to enquire about our moral accountability. At the same time, we avoid focusing solely on violence against women, and open up our analysis and policies to all forms of genderbased violence. Undoubtedly, the victim configuration has served juridical, social and healthcare purposes. However, a radical transformation of violence cannot be acted upon without questioning the sole legitimacy of the state in the eradication of the problem, as the indignant configuration displays and the women's movement has long and previously established. Thus, the community and media's responsibility emerges. From this perspective, women cannot be framed in such a way as to be held accountable for the violence they suffer. The community needs to be addressed for its role in sustaining violence and for the lack of tools in place for women to empower themselves in the peaceful transformation of gender conflicts.

\section{RECOMMENDED READING}

Adelman, Madelaine. 2009. "Domestic violence." in P. Essed, D. T. Goldberg and A. Kobayashi (eds.), A Companion to Gender Studies. Oxford: Wiley-Blackwell.

Berns, Nancy. 2004. Framing the Victim: Domestic Violence and Social Problems. New Jersey: Transaction.

Butler, Judith. 1990. Gender Trouble. London: Routledge.

Butler, Judith. 2005. Giving account of oneself. New York: Fordham University Press.

Butler, Judith. 2008. "Gender is Extramoral." Interview with Judith Butler. Judith Butler and Fina Birulés (Interviewer), Centre de Cultura Contemporània, Barcelona. Accessible in: http://www.egs.edu/faculty/judith-butler/articles/gender-isextramoral/ [Date of visit: May $\left.5^{\text {th }} 2011\right]$.

Confortini, Catia. 2006. "Galtung, Violence, and Gender: The Case for a Peace Studies/Feminism Alliance." Peace and Change: 31(3), 333-367.

De Lauretis, Teresa. 1989. "The Violence of Rhetoric: Considerations on Representation and Gender." in Nancy Armstrong y Leonard Tennenhouse (eds.), The Violence of Representation. London: Routledge.

Engle Merry, Sally. 2009. Human Rights and Gender Violence: Translating International Law into Local Justice. Chicago: University of Chicago Press.

Hill Nettleton, Pamela. 2011. 'Domestic Violence in Men's and Women's Magazines: Women Are Guilty of Choosing the Wrong Men, Men Are Not Guilty of Hitting Women." Women's Studies in Communication: 34(2), 139-160. 
Oliver, Kelly. 2004. "Witnessing and Testimony." Parallax: 10(1), 79-88.

Weldon, S. Laurel and Htun, Mala N. 2012. "The Civic Origins of Progressive Policy Change: Combating Violence against Women in Global Perspective, 1975-2005." American Political Science Review: 106(3), 548-569.

María José Gámez Fuentes is Reader on Gender and Cultural Studies in the Department of Communication Sciences at Universitat Jaume I (Castellón, Spain), Vice Head of the Research Institute for Social Development and Peace and member of the Institute for Feminist Research of the same university. Her work focuses on the politics of representing cultural violence and how to transform gender conflicts towards cultures of peace. 